\title{
REGULATION OF THE SODIUM PUMP IN HYPEROXIC LUNG INJURY
}

\author{
David H. Ingbar, Joseph M. Lasnier, O. Douglas Wangensteen, and Christine H. Wendt \\ Departments of Medicine, Physiology and Pediatrics \\ University of Minnesota School of Medicine \\ Minneapolis, MN 55455
}

\section{INTRODUCTION}

A major component of the early lesion in the adult respiratory distress syndrome (ARDS) is alveolar edema. Considerable data suggests that decreasing alveolar flooding improves the outcome from acute lung injury (ALI). Studies in humans with ARDS demonstrate that prognosis correlates with the capacity to resorb fluid (Matthay 1990). Retrospective studies indicate that patients with fluid balance out>in, lesser weight gain, lower pulmonary capillary wedge pressures or diuretic treatment have greater survival rates. It is not surprising that decreasing the degree of early alveolar flood could decrease the subsequent need for high pressure ventilation or high levels of oxygen - thus avoiding amplification of the injury.

Active resorption of alveolar sodium and fluid is critical for edema resolution and avoiding further amplification of lung injury (O'Brodovich 1995, Matthay 1996). It also is critical for the normal transition to postnatal breathing (O'Brodovich 1991). In the normal human and rodent lung many substances augment alveolar sodium and fluid resorption. Oxidant stress is a major mechanism of damage during ALI and this stress persists due to the neutrophilic inflammation and use of high levels of inspired oxygen in many patients. Oxidative injury can either inhibit or augment active sodium transport, depending on a number of variables (Ingbar 1997b, 1998). Recently we demonstrated that even the injured alveolar epithelium is capable of active fluid resorption and this can be stimulated by $\beta$-adrenergic agonists, such as terbutaline (Lasnier). This chapter examines the effects of oxidants on one component of the sodium resorption system, the sodium pump - Na,K-ATPase; the sodium channel is the other critical component of this system.

Clearance of sodium and water from the alveolar space is primarily mediated by a combination of an apical amiloride-sensitive sodium channel (Matalon 1996) and the basolateral sodium pump, $\mathrm{Na}, \mathrm{K}-\mathrm{ATP}$ ase (Matthay 1996). The importance of this pathway is supported by inhibitor and ion substitution studies in living animals, isolated perfused lungs and cultured type II alveolar epithelial cell monolayers (Matalon 1991, Saumon). We have examined the mechanisms by which oxidant stress affects alveolar epithelial solute and fluid resorption, and particularly on the sodium pump, the major 
basolateral pathway for sodium transport.

\section{Na,K-ATPase STRUCTURE}

$\mathrm{Na}, \mathrm{K}-\mathrm{ATPase}$, is a ubiquitous heterodimeric transmembrane protein composed of $\alpha 1$ and $\beta 1$ subunits in a 1:1 ratio (Horisberger). The $\alpha 1$ subunit is a polypeptide of approximately $96-112 \mathrm{kD}$ with 7 membrane spanning domains that catalyzes the movement of $\mathrm{Na}+$ and $\mathrm{K}+$, is phosphorylated by ATP and binds the specific inhibitor ouabain (Skou). It has $3 \mathrm{mRNA}$ isoforms whose expression varies in different tissues and in development (Jewell). Alpha-1 is the predominant form in epithelial tissues (Sweadner) including ATII cells (Nici, Schneeberger), but cultured type I-like cells may express $\alpha 2$ (Ridge). The $\beta$ subunit has 3 isoforms and is a glycosylated polypeptide with a peptide core of $\sim 35 \mathrm{kD}$. It targets the assembled molecule to the plasma membrane (Geering) through the C-terminal extracellular domain of the $\beta$ subunit. The $\beta$ subunit also is necessary for $\mathrm{K}$-dependent reactions (McDonough 1990a). The $\beta 1$ isoform is ubiquitous, whereas $\beta 2$ is in brain only.

\section{Na,K-ATPase REGULATION}

The Na,K-ATPase is regulated at multiple levels and by short and long term mechanisms (Bertorello 1995 a,b), as befits an enzyme that consumes up to $30 \%$ of cellular ATP. Regulation of the sodium pump can be achieved rapidly by altering the activity of the enzyme or by moving it to and from the plasma membrane. Pump activity is rapidly increased by lower $\mathrm{K}^{+}$or higher $\mathrm{Na}^{+}$ intracellular ion concentrations, and by hormones such as glucocorticoids (GCs), mineralocorticoids, $\beta$ adrenergic agonists and thyroid hormone (McDonough 1990b). Beta agonists increase sodium resorption and $\mathrm{Na}, \mathrm{K}-\mathrm{ATPase}$ activity in alveolar type II (ATII) cells (Suzuki). In some cell types, $\mathrm{Na}, \mathrm{K}-\mathrm{ATPase}$ activity can be inhibited by dopamine, endothelin or PGE2 and stimulated by vasopressin, or growth factors (Berterello). Hypoxia decreased ATII cell sodium pump activity, presumably through impaired calcium homeostasis (Planes).

Post-transcriptional regulation is important at multiple levels (Gick). Unequal ratios of $\alpha$ and $\beta$ mRNA and protein concentrations are present in many tissues (Lingrel), even though the functional sodium pump enzyme has 1:1 stoichiometry. The mRNA degradation rates can change with cell differentiation and this may contribute to changing ratios of the subunits (Chambers). Translation is regulated and this probably accounts for some of the differences in the ratios of subunit mRNAs and proteins. The mRNA for $\alpha 1$ is translated less efficiently than $\beta 1$ due to the $\alpha 1$ mRNA's 3' untranslated region (UTR) which is extremely G-C rich (Devarajan). Once the subunits are translated, they can not leave the endoplasmic reticulum without assembly into $\alpha-\beta$ heterodimers (Geering), glycosylation and disulfide bond formation (Beggah). After assembly, they undergo an ill-defined maturation and then are transported into the cytoplasmic membrane over 1-4 hours to generate active pump that can bind ouabain (Caplan, Mircheff). There is an inactive, endogenous pool of $\mathrm{Na}, \mathrm{K}$ ATPase that that recycles from plasma membrane sodium pump. Movement of pump molecules between this intracellular pool and the plasma membrane can be stimulated, as by insulin in muscle, but the regulatory factors are not well understood. Mechanical ventilation or stretch may recruit Na,KATPase in ATII cells from this pool. The $\alpha$ subunit can be phosphorylated at several amino acids by either protein kinases $\mathrm{C}$ or $\mathrm{A}$ (Feschenko, Beguin, but the functional consequences vary depending on the cell type, the particular kinase and the stimulant (Berterello). Normally the pump molecules in the plasma membrane do not operate at peak capacity, providing an important mechanism for short term regulation. Hormones such as glucocorticoids (GCs), thyroid hormone, aldosterone and catecholamines stimulate both short term and long term (transcriptional) increases in pump function (Ewart). Degradation rates of the two subunits also can be differentially affected, changing the balance of alpha and beta subunits (Lescale-Matys). The wide repertoire of potential regulatory 
mechanisms makes studying the response of the Na,K-ATPase to injury much more complex.

\section{TRANSCRIPTIONAL REGULATION OF Na,K-ATPase}

Transcriptional regulation is common (reviewed in Lingrel), and likely plays a role during lung development (Ingbar 1996). Pump transcription in cultured cells usually is upregulated by increased intracellular Na or lower K levels (McDonough1990b) and hormones such as GCs, aldosterone and T3 (Horisberger). The $\mathrm{Na}, \mathrm{K}-\mathrm{ATPase}$ isoforms belong to a multigene family and they are expressed in a tissue-specific and developmentally regulated manner (reviewed in Lingrel). Since the subunit genes are on different chromosomes, transcription may be independently regulated. Both subunits have $>70 \%$ homology between isoforms of each subunit and there is significant interspecies homology of the $\mathrm{Na}, \mathrm{K}-\mathrm{ATPase}$ coding and promoter sequences. For example, rat and sheep have $97 \%$ homology of the $\alpha 1$ isoform.

For the rat $\alpha 1$ subunit, the major transcription initiation site is 262 base pairs upstream from the translation initiation site and is preceded by a TATA box at position -32 (Kawakami 1993, 1996). The factors regulating $\alpha 1$ gene transcription are partially defined. Included in the 5' flanking region are 2 Sp1 TF binding sites, two putative GC response element (GRE) half consensus sequences (Yagawa 1990) and a consensus cAMP response element (CRE). The human gene has a TATA box and 5 Sp1like elements (Shull 1990). Two positive regulatory regions in the rat $\alpha 1$ subunit promoter are (1) at 155 and -49 bp and (2) an "Atpl $\alpha 1$ " regulatory element or "ARE" at -94 to -69 bp that binds both common (ARE C1 and C2) and cell type-specific transcription factors (ARE C3) (Yagawa 1992). This sequence is conserved across rat, horse and human genes, but is not present in other $\mathrm{Na}, \mathrm{K}$ ATPase subunit promoters. At least 7 ARE-binding factors have been identified by gel mobility shift assays and southwestern cloning (Watanabe). One stimulatory transcription factor (TF), AREC3, is a homologue of the Drosophila sine oculis (Six) gene product that is required for visual system development, but is distinct from other homeodomain proteins. It is present at low levels in adult mouse lung, but otherwise has not been assessed in lung tissue. AREB6 is a zinc finger protein that can regulate Atp $1 \alpha 1$ positively or negatively, depending on cell type and conformational state of the protein. It is a 5' extended version of Nil-2, a negative regulator of the interleukin-2 gene. Across multiple cell lines, activating transcription factor-1 (ATF-1)/ CRE binding protein (CREB) heterodimers bound to the $-61 /-72$ region of the $\alpha 1$ promoter and were required for transcription (Kobayashi). Although these TFs are ubiquitous and probably are required for basal transcription of many genes, they can be regulated by cAMP, $\mathrm{Ca}$, and transforming growth factor- $\alpha(\mathrm{TGF}-\alpha)$. Recent in vivo footprinting found that rat tissue-specific transcriptional control involved cooperation between a canonical GC box at $-57 /-49$ that binds an Spl-like TF and the ATF region (-72/-65) (Nomoto). There also were DNAse I hypersensitive sites at $-83 /-80$ in liver and kidney, but not brain. HeLa cells treated with aldosterone after mineralocorticoid receptor transfection had less cAMP-inducible $\alpha 1$ gene transcription of the $-103 /-57$ promoter region (Ahmad), but little is known of mineralocorticoid regulation. The human $\alpha 1$ gene has three potential thyroid hormone response elements, but only one is functional (Feng). In summary a number of potential TFs have been identified, but their presence and function in the lung are virtually undefined.

Much less is known about transcriptional regulation of the $\beta 1$ subunit gene. The rat gene's promoter contains a potential TATA box at position -31, four GC rich boxes, a CRE-like sequence and two sites with putative half consensus thyroid response element sequences TRE-1 and TRE-2 (Liu). The human gene consists of six exons and has two major and three minor transcription initiation sites.

\section{LUNG ION TRANSPORT AND Na,K-ATPase}

Although present to some extent in all cells, the sodium pump is found in high density on the 
basolateral membranes of epithelial cells specialized for $\mathrm{Na}$ transport. Net vectoral ion transport across the alveolus resorbs fluid and maintains a dry alveolus. The joint importance of $\mathrm{Na}, \mathrm{K}-\mathrm{ATP}$ ase and the sodium channel in salt and water resorption across the alveolar epithelium is supported by studies of intact animals, intact lungs and cultured cells (Saumon, Matalon 1991, Matthay 1996).

The ion transport properties of adult type II cells recently were reviewed (Matalon 1991). Sodium may enter the apical membrane by at least 3 mechanisms: Na channels, Na-glucose cotransport or $\mathrm{Na}-\mathrm{H}+$ exchange, but $\mathrm{Na}$ channels are quantitatively predominant, at least in adult cells. There likely are several different types of Na channels in alveolar epithelial cells (AECs) (Matalon 1996), since the amiloride affinity and conductance properties differ between freshly isolated and cultured ATII cells. In alveoli, this ubiquitous enzyme is detected primarily on the basolateral surface of type II cells (Nici, Schneeberger), but has not been detected on type I AECs in vivo. One group detected increases in $\alpha 2$ isoform and decreases in $\alpha 1$ with time that ATII cells are in culture, suggesting that ATI cells may have $\alpha 2$ (Ridge), but this has not been established in vivo. The beta subunit has not yet been localized in lung. The density of sodium pump on type II cells supports their importance in maintaining a dry alveolus, although type I cells also may contribute to fluid clearance. The $\mathrm{Na}, \mathrm{K}$ ATPase is the primary sodium exit pathway via the basolateral membrane. Both sodium pump and channel are needed for $\mathrm{Na}$ transport, but it is not clear which is limiting under normal or pathologic circumstances - especially since their activityusually changes in parallel. In addition to clearing alveoli of fluid, the low intracellular sodium concentration maintained by Na,K-ATPase allows sodiumcoupled co-transport of amino acids, glucose and other vital substrates into ATII cells.

\section{REGULATION OF LUNG SODIUM TRANSPORT AND RESPONSE TO INJURY}

Many factors can stimulate sodium and fluid resorption in the normal lung (reviewed in Matthay 1996), including catecholamines, dobutamine, dopamine, keratinocyte growth factor (KGF), aldosterone, hepatocyte growth factor (HGF), transforming growth factor (TGF $\alpha$ ), cAMP, endotoxin, Pseudomonas exotoxin A, and tumor necrosis factor- $\alpha$ (TNF- $\alpha$ ). It is not clear if these factors act directly or through indirect mechanisms and what transporters they influence. Whenever tested, inhibitors of sodium channel or $\mathrm{Na}, \mathrm{K}-\mathrm{ATPase}$ significantly reduced alveolar fluid resorption. In cultured ATII cells, catecholamines and epidermal growth factor (EGF) (Borok) augmented transepithelial $\mathrm{Na}$ transport and terbutaline stimulated $\mathrm{Na}, \mathrm{K}$-ATPase activity independent of changes in intracellular sodium concentration (Suzuki). Important recent studies demonstrated that $\beta$-adrenergic agonists increased alveolar fluid clearance several fold in ex vivo human and rat lungs (Sakuma).

The impact of lung injury on alveolar fluid clearance and sodium transport has been examined in several injury models (Matthay 1996). Sepsis, pneumonia and endotoxin augmented clearance, in part through increased $\mathrm{TNF} \alpha$. Endotoxin-stimulated macrophages impaired lung epithelial transport (Compeau) through a nitric oxide (NO)-dependent mechanism. Intravascular and intratracheal dibutyryl cAMP attenuated edema formation in a phosgene-induced lung injury through activation of prostaglandins. In permeability pulmonary edema induced by napthyl-thiourea, there is increased sodium pump acitivity and alveolar solute resorption during recovery (Zuege).

\section{Na,K-ATPase AND REACTIVE OXIDANT SPECIES}

The effects of oxidant stress on Na,K-ATPase and alveolar fluid resorption have varied in different models studied. This also has been demonstrated in many different cell types from other organs (Ingbar 1997). Severe oxidant stress may inhibit general protein synthesis, inhibit sodium pump function or increase protein degradation. Recently we reviewed the multiple reported effects of oxidants on Na,K-ATPase function in different systems (Ingbar 1997). The studies of oxidant effects by other groups will first be reviewed and then the results of our studies on the lung Na,K-ATPase 
will be summarized.

Acute severe hyperoxia, an injury with little type II cell proliferation, has variable effects on fluid resorption depending on severity of injury. Moderate injury has normal or increased resorption (Zheng, Garat, Carter 1997b), but severe injury can decrease clearance (Olivera 1995). In spite of increased permeability, the lung can still resorb fluid actively (Lasnier, Garat). Short periods of hyperbaric hyperoxia increase rat lung Na,K-ATPase mRNA levels (Harris). KGF is a growth factor for ATII cells in vivo and protects lungs from $\mathrm{HCl}$, hyperoxic, bleomycin and radiation-induced injuries (Panos). The mechanism of KGF protection is not clear - it may be due to type II cell proliferation, increased surfactant decreased apoptosis or, in part, increased fluid clearance.

Less severe or more subacute injury can stimulate type II cell proliferation and may increase resorption through this mechanism. For example, chronic hyperoxia causes ATII proliferation with increased $\mathrm{Na}$ channels (Yue 1995) and Na,K-ATPase (Olivera 1994), but fluid clearance increased only in some rats (Yue 1997).

Multiple methods of sodium pump inhibition by oxidants are possible (Boldyrev), including direct protein oxidation (such as sulfhydryl oxidation), peroxidation of surrounding membrane lipid, depletion of intracellular energy stores, uncoupling of energy utilization and ion transport (Elmosehi) or changes in ionic gradients. ROS can aggregate or fragment many proteins and may provide denatured substrates for protease degradation (Davies, Zolotarjan). The sodium pump's sensitivity to ROS may be due to oxidation of critical cysteine residues and disulfide bonds that maintain the enzyme conformation (Gevondyan). While the enzyme functions after all the $\alpha 1$ subunit cysteines have been mutated (Lane), the $\beta 1$ disulfides are critical for $\alpha$ subunit catalytic activity (Ueno). Other amino acids, such as tyrosines, may undergo modification to nitrotyrosine or chlorotyrosine (Heinecke) that could alter function, but has not yet been demonstrated for Na,K-ATPase. The effects of hyperoxia and ROS on sodium pump activity likely vary with different reactive oxygen species, the severity of injury, and cell type. Reactive oxygen species inhibit Na,K-ATPase isolated from canine kidneys (Huang) and myocardiocytes (Haddock) and activated neutrophils inhibit Na,K-ATPase in vitro (Julin), likely through oxidant mechanisms. Nitric oxide inhibits sodium pump activity in mouse proximal tubule epithelial cells. In the brain, lipid peroxidation is the likely mechanism of decreased activity due to modification of sodium pump binding sites for ATP, $\mathrm{K}$, and $\mathrm{Na}$ (Mishra). In ATII cells, $\mathrm{H} 2 \mathrm{O} 2$ or peroxynitrite can inhibit the pump with differential effects from the apical and basal sides (Clerici, Hu, Kim).

In contrast, in at least some circumstances oxidants can stimulate $\mathrm{Na}, \mathrm{K}$-ATPase. Reactive oxygen species increase the activity of the sodium pump in intact endothelial cells (Elliott, Meharg). While protein kinases are activated in this model, they do not seem to be causal (Charles). Nitrogen dioxide augments airway epithelial sodium pump (Robison). The apparent contradiction between these results and the inhibition noted above may be partially a function of when the effect is examined. In one study of ATII cells, high levels of hydrogen peroxide initially inhibited the pump, followed shortly by rebound upregulation (Gonzalez-Flecha) - again consistent with homeostatic defense of this vital cell function.

We analyzed the effects of hyperoxia on $\mathrm{Na}, \mathrm{K}-\mathrm{ATPase}$ mRNA, protein and activity in three lung injury models and have ion transport data for two of the three models. The basis for our experimental design was that this comprehensive approach would provide information about the important steps affected in the response to hyperoxia and control of Na,K-ATPase function in the lung. The models used were (1) in vivo hyperoxia of rats with analysis of peripheral lung biochemical parameters and isolated perfused lung or in situ sodium transport; (2) type II cells isolated from rats after 60 hours of in vivo hyperoxia; and (3) rat alveolar epithelial cells exposed in vitro to hyperoxia for 24-48 hours. We discovered that the Na,K-ATPase mRNA-protein-activity parameters did not change in parallel, but there were many consistent responses in the different models. For example, across each model, Na,K-ATPase gene expression consistently increased. The type II cell protein level 
changes were complex, with maintained $\beta-1$, but decreased $\alpha$ subunit protein in acute hyperoxia, followed by return to normal levels. In terms of transport, we were surprised to discover heterogeneity of the response of unidirectional active sodium resorption in the rats (Carter 1997b). In intact type II cells (models 2 and 3 ) steady state sodium pump transport activity was normal, but the sodium pump Vmax of membrane preparations decreased. Thus these data indicate that sodium pump and transport are affected and regulated in at least several discrete ways during hyperoxia - increased gene expression; differential changes in relative expression of the $\alpha-1$ and $\beta-1$ subunit proteins; and modification of peak enzyme capacity for pump molecules in the plasma membrane with maintained steady state functional activity. It is very likely that there is simultaneous oxidative injury to some pump molecules while there is a homeostatic increase in transcription accompanied by altered intracellular regulation.

In a standard in vivo acute hyperoxic model (60 hour $>95 \%$ oxygen) (Thet, Crapo), $\alpha 1$ and $\beta 1$ mRNA increased early and were 3-5 fold elevated at 60 hours when the alveolar septae were widened with interstitial and mild alveolar edema present, but AECs appeared normal (Nici). No new cell population with sodium pump subunit staining was seen. Levels of $\alpha 1$ and $\beta 1$ subunit antigenic proteins increased significantly by day 1 after $\mathrm{O}_{2}$ exposure ended and remained elevated through 7 days of recovery. We measured the active (amiloride-inhibitable) and total unidirectional sodium resorption from the alveolar space (Carter 1997b). We were surprised to discover heterogeneity in the degree of injury - as reported in chronic hyperoxia (Yue 1997). The more severely injured rats had augmented active $\mathrm{Na}$ resorption, whereas the mildly injured rats had decreased active $\mathrm{Na}$ resorption consistent with upregulation with worsening injury.

ATII cells were studied from rats after 60 hours of in vivo 100\% oxygen (Carter 1997a). Ouabain-sensitive $\mathrm{Rb}$ uptake into intact ATII cells was normal with hyperoxia, however, the sodium pump Vmax of ATII cell membranes was reduced to $75 \%$ of control. The ATII cell $\alpha 1$ subunit protein decreased in hyperoxia while the $\beta 1$ was stable. The mRNA levels of both subunits increased. Thus levels of mRNA, protein and enzyme activity did not respond in parallel to hyperoxia and steady state activity of the intact cells correlated best with the amount of $\beta 1$ subunit protein.

We developed an in vitro hyperoxic ATII cell model to eliminate interactions with other cell types and hormonal influences, enabling us to study the effects of hyperoxia more directly (Carter 1994). One day after recovery from isolation, normal rat ATII cells were exposed to $95 \% \mathrm{O}_{2} / 5 \% \mathrm{CO}_{2}$ in vitro. The cells demonstrated $\sim 25 \%$ death with increased Erythrosin B uptake and decreased DNA/plate at 48 , but not 24 , hours. Within 24 hours of hyperoxia, the type II cells increased levels of $\mathrm{Na}, \mathrm{K}$-ATPase mRNA for both subunits, with $\beta 1$ rising more than $\alpha 1$, but the $\alpha 1$ protein level was decreased and the $\beta 1$ level was unchanged. The sodium pump Rb uptake of the intact cells was normal, but the Vmax of cell membranes again was reduced significantly. Results in this model were almost identical to those in the ATII cells isolated after in vivo injury, supporting the direct effects of hyperoxia in effecting these changes in ATII cells in this much simpler system.

An important general scientific question is the mechanisms through which oxidants and oxygen tension affect gene expression in the lung (Fanburg). To study the detailed mechanism of $\mathrm{Na}, \mathrm{K}$ ATPase gene upregulation in hyperoxia, we screened for hyperoxic induction of $\mathrm{Na}, \mathrm{K}-\mathrm{ATPase} \mathrm{mRNA}$ in other cell lines. Two alveolar epithelial cell (AEC) lines, A549 and MP48 cells did not increase $\mathrm{Na}, \mathrm{K}$-ATPase mRNA in response to hyperoxia; but they do not form tight junctions in cell culture. In contrast, the renal tubular MDCK (Madin-Darby canine kidney) epithelial cells increased Na,K-ATPase $\alpha 1$ and $\beta 1 \mathrm{mRNA}$ in response to hyperoxia in vitro (Wendt). Hyperoxia increased the transepithelial resistance of MDCK cells cultured on Millicell HA (Millipore) filters, suggesting that increased functional $\mathrm{Na}, \mathrm{K}-\mathrm{ATPase}$ and consistent with increased dome formation (Dreher). We sought to determine the mechanism of increased $\mathrm{Na}, \mathrm{K}-\mathrm{ATPase}$ steady state mRNA levels. The mRNA half lives of the $\alpha 1$ and $\beta 1$ subunit mRNAs did not significantly change with hyperoxia, with approximate halflives for the $\alpha 1$ subunit were $4.4 \mathrm{hrs}$ in normoxia and $4.7 \mathrm{hrs}$. in hyperoxia and for the $\beta 1$ subunit 
were $5.9 \mathrm{hrs}$. in normoxia and $6.0 \mathrm{hrs}$. in hyperoxia. In nuclear run-on assays on both MDCK and type II cells after normoxia or 12 hrs. of hyperoxia, hyperoxia-induced transcription of both subunits in both cell types: 1.7 fold for $\alpha 1$ subunit and $\sim 3$ fold for $\beta 1$ subunit in type II cells and 1.3 fold for $\alpha 1$ subunit and 3.0 fold for $\beta 1$ subunit in MDCK cells. Thus the increased sodium pump gene expression was primarily due to increased transcription.

To identify hyperoxia-sensitive regulatory regions of the gene promoters, MDCK cells were transfected with wild type and 5' deletions of $\alpha 1$ (1537bp) and $\beta 1$ (817 bp) subunit promoter-luciferase reporter constructs (gifts of K. Kawakami, Dept. Biology, Jichi Medical School and G. Gick, SUNY Brooklyn, respectively) (Wendt). Promoter activity of full length and multiple 5' deletion constructs of the $\alpha 1$ construct did not change with hyperoxia, suggesting that transcriptional control may lie outside of the 5' $1537 \mathrm{bp}$ region. In contrast, hyperoxia increased $\beta 1$ luciferase activity two fold relative to normoxia. Transfection with two $\beta 15^{\prime}$ ' promoter deletion constructs identified a region between -102 and -41 required for increased promoter activity with hyperoxia. Sequence analysis of this region did not identify consensus sequences for known oxidant-sensitive transcription factors, such as AP-1, ARE (Rushmore), or NFKB. The region is GC rich and has partial sequence homology with an SP-1 site, but this redox-sensitive transcription factor usually is believed to be important for basal transcription..

We confirmed that this 61 bp $\beta 1$ promoter region (-102 to -41$)$ was specific and sufficient for hyperoxia induction, by subcloning oligonucleotides spanning this region into a luciferase vector containing a minimal promoter of the mouse mammary tumor virus (MMTV) that alone was not inducible by hyperoxia. When transfected into MDCK cells, hyperoxia induced promoter activity for both the larger oligonucleotide $(-157$ to -38$)$ and even more with the smaller dimer of -84 to -44 . Thus a 40 bp region between -84 and -44 is necessary and sufficient for hyperoxic induction. The specific transcription factors in addition to SP1 that interact with this region are being determined.

\section{PHYSIOLOGIC RELEVANCE OF ALTERING SODIUM PUMP IN LUNG INJURY}

A major question concerning clinical strategies to increase fluid resorption is whether they still work in high permeability injury states. As discussed by Dr. Matthay, this now is being demonstrated in several lung injury models. We developed an in situ method for measuring alveolar fluid resorption in warm dead rats (Lasnier). Fluid absorption reflected changes in alveolar fluid volume. In this model, terbutaline stimulated fluid resorption approximately 2 fold in both normal rat lungs and lungs injured by 60 hours of hyperoxia. In both situations the terbutaline-induced increased absorption was prevented by ouabain. There also was a statistical trend towards greater resorption induced by hyperoxia itself.

\section{SUMMARY}

Oxidants have been intensively studied for many years because of their importance as a pathophysiologic mechanism of disease. However, relatively little is known about their impact on certain fundamental cellular processes, such as translation, and on the integrated response of transporting epithelia. A disadvantage of studying oxidants is their complex multiplicity of effects - as demonstrated by the non-parallel changes in Na,K-ATPase mRNA, protein and activity we have observed. Our studies indicate that multiple simultaneous effects likely occur, including inhibition of peak Na,K-ATPase capacity and increased gene transcription. Understanding the mechanisms by which oxidants impact ATII cell monolayer sodium transport and sodium pump oxidation, translation and transcription should significantly augment our ability to design therapeutic strategies likely to succeed in upregulating alveolar fluid resorption in ARDS and other conditions with alveolar flooding. It also will add knowledge about this critical enzyme, important for many cell functions in a variety of 
organs.

\section{ACKNOWLEDGEMENTS:}

The experimental work by the authors reported herein was supported by grants from the NIH (Acute Lung Injury SCOR HL50152 for DHI and ODW, K08HL03114 To CHW), the American Heart Association (Research Grant-In-Aids to DHI and CHW) and the American Lung Association (Career Investigator Award to DHI and a Research Fellowship to JL).

\section{LITERATURE CITED:}

Ahmad M, RM Medford. Evidence for the regulation of Na,K-ATPase $\alpha-1$ gene expression through the interaction of aldosterone and cAMP-inducible transcriptional factors. Steroids 60:147-152, 1995.

Beggah AT, P Jaunin, K Geering. Role of glycosylation and disulfide bond formation in the $\beta$ subunit in the folding and functional expression of Na,K-ATPase. J Biol Chem 272:10318-10326, 1997.

Beguin P, A Beggah, S Cotecchia, K Geering. Adrenergic, dopaminergic and muscarininc receptor stimulation leads to PKA phophorylation of Na,K-ATPase. Am J Physiol 270:C131-C1347, 1996. Bertorello AM, AI Katz. Regulation of Na-K pump activity: pathways between receptors and effectors. NIPS 10:253-259, 1995.

Bertorello AM, Katz AI. Short-term regulation of renal Na,K-ATPase activity: physiological relevance and cellular mechanisms. Am J Physiol 265:F743-55, 1995

Berthiaume Y: Effects of exogenous cAMP and aminophylline on alveolar and lung liquid clearance in anesthetized sheep. J Appl Physiol 70:2490-2497, 1991.

Boldyrev A, E Kurella: Mechanism of oxidative damage of dog kidney Na/K-ATPase. Biochem Biophys Res Comm 222:483-487, 1996.

Borok Z, Hami A, Danto SI, Lubman RL, Kim KJ, Crandall ED: Effects of EGF on alveolar epithelial junctional permeability and active sodium transport. Am J Physiol 270:L559-565, 1996. Caplan MJ, B Forbush, GE Palade, JD Jamieson. Biosynthesis of the Na,K-ATPase in MDCK cells: activation and cell surface delivery. J Biol Chem 265:3528-2534, 1990.

Carter EP, Duvick SE, Wendt CH, Dunitz J, Nici L, Wangensteen OD, Ingbar DH. Hyperoxia increases active alveolar $\mathrm{Na}+$ resorption in vivo and type II cell Na,K-ATPase in vitro. Chest 105:75S78S, 1994.

Carter, E.P., Wangensteen, O.D., O'Grady, S.M. and Ingbar, D.H., Effects of hyperoxia on type II cell Na-K-ATPase function and expression. Am. J. Physiol. (Lung) 272:L542-L551, 1997a.

Carter E, Wangensteen OD, Carter EP, Dunitz J, Ingbar DH: Hyperoxic effects on alveolar sodium resorption and lung Na,K-ATPase. Am. J. Physiol. 273:L1191-L1202, 1997b.

Chambers SK, Gilmore-Hebert M, Kacinski BM, Benz EJ: Changes in Na,K-ATPase gene expression during granulocytic differentiation of HL60 cells. Blood 80:1559-1564, 1992 Charles A, Dawicki DD, Oldmixon E, Kuhn C, Cutaia M, Rounds S. Studies on the mechanism of short-term regulation of pulmonary artery endothelial cell $\mathrm{Na} / \mathrm{K}$ pump activity. J Lab Clin Med 130:157-168, 1997.

Clerch LB, Massoro D. Oxidation-reduction-sensitive binding of lung protein to rat mRNA. $J$ Biol Chem 267:2853-2855, 1992

Clerici C, Friedlander G, Amiel C: Impairment of sodium-coupled uptakes by hydrogen peroxide in alveolar type II cells: protective effect of a-Tocopherol. Am J Physiol 262:L542-548, 1992

Compeau CG, OD Rotstein, H Tohda, Y Marunaka, B Rafii, AS Slutsky, H O'Brodovich:

Endotoxin-stimulated alveolar macrophages impair lung epithelial $\mathrm{Na}$ transport by an L-Argdependent mechanism. Am J Physiol 266:C1330-C1341, 1994. 
Crapo JD: Morphologic changes in pulmonary oxygen toxicity. Ann Rev Physiol 48:721-731, 1986.

Davies KJA, ME Delsignore, SW Lin: Protein damage and degradation by oxygen radicals, I.

General aspects \& II. Modification of amino acids J Biol Chem 262:9895-9901;9902-9907, 1987.

Devarajan P, Gilmore-Hebert M, Benz EJ: Differential translation of the Na,K-ATPase subunit mRNAs. J. Biol. Chem. 267:22435-22439, 1992.

Dreher D, Rochat T. Hyperoxia induces alkalinization and dome formation in MDCK epithelial cells. Am J Physiol 262:C358-364, 1992.

Elliot SJ, Schilling WP. Oxidant stress alters $\mathrm{Na}+$ pump and $\mathrm{Na}+-\mathrm{K}^{+}-\mathrm{Cl}^{-}$cotransporter activities in vascular endothelial cells. Am J Physiol 263:H96-H102, 1992.

Elmoselhi AB, Butcher A, Samson SE, and Grover AK. Free radicals uncouple the sodium pump in pig coronary artery. Am J Physiol 266:C720-C728, 1994.

Ewart HS, A Klip. Hormonal regulation of the Na-KATPase: mechanisms underlying rapid and sustained changes in pump activity. Am J Physiol 269:C295-311, 1995.

Fanburg BL, Massaro DJ, Cerutti PA, Gail DB, Berberich MA. Regulation of gene expression by $\mathrm{O}_{2}$ tension. Am J Physiol 263: L235-L241, 1992.

Feng J, Orlowski J, Lingrel JB: Identification of a functional thyroid hormone response element in the upstream flanking region of the human Na,K-ATPase $\alpha-1$ gene. Nucl. Acids Res. 21:26192626, 1993.

Feschenko MS, KJ Sweadner: Conformation-dependent phosphorylation of Na,K-ATPase by protein kinase A and protein kinase C. J Biol Chem 269:30436-30444, 1994.

Garat C, M Meignan, MA Matthay, DF Luo, C Jayr: Alveolar epithelial fluid clearance mechanisms are intact after moderate hyperoxic lung injury in rats. Chest 111:1381-88, 1997. Geering K. Subunit assembly and posttranslational processing of $\mathrm{Na}^{+}$-pumps. Acta Physiol Scand 146:177-181, 1992.

Gevondyan NM, VS Gevondyan, NN Modyanov: Location of disulfide bonds in the Na,K-ATPase $\alpha$ subunit. Biochem Molecul Biol Intl 30:347-355, 1993.

Gick GG, Ismail-Beigi F, Edelman IS. Thyroidal regulation of rat renal and hepatic Na,K-ATPase gene expression. J Biol Chem 263:16610-16618, 1988.

Gonzalez-Flecha B, Evelson P, Ridge K, Sznajder JI. Hydrogen peroxide increases $\mathrm{Na}^{-}$/ $\mathrm{K}^{-}$ATPase function in alveolar type II cells. Biochim Biophys Acta 1290:46-52, 1996.

Haddock, PS, MJ Shattock, DJ Hearse. Modulation of cardiac Na-K pump current: role of protein and nonprotein sulfhydryl redox status. Am J Physiol 269:H297-H307, 1995.

Harris ZL, Ridge KM, Gonzalez-Flecha B, Gottlieb L, Zucker A, Sznajder JI. Hyperbaric oxygenation upregulates rate lung Na,K-ATPase. Eur Respir $J$ 9:472-477, 1996

Heinecke JW, W Li, GA Francis, JA Goldstein: Tyrosyl radical generated by myeloperoxidase catalyzes the oxidative cross-linking of proteins. J Clin Invest 91:2866-2872, 1993.

Horisberger, J-D. The Na,K-ATPase: Structure-Function Relationship. R.G. Landes Co., Austin, 1994. $\mathrm{Hu} \mathrm{P}$, Zhu L, Ischiropoulos $\mathrm{H}$, Matalon S. Peroxynitrite inhibition of oxygen consumption and ion transport in alveolar type II cells. Am J Physiol 266:L628-34, 1994.

Huang W-H, Wang Y, Askari A. $\left(\mathrm{Na}^{+}+\mathrm{K}^{+}\right)$-ATPase: inactivation and degradation induced by oxygen radicals. Int $J$ Biochem 24:621-626, 1992.

Ingbar DH, Duvick S, Burns CA, Jacobsen E, Dowin R, Savik SD, Gilmore-Hebert M, Jamieson JD. Developmental Regulation of Lung Na, K-ATPase. Am. J. Physiol. (Lung) 270:L619-629, 1996. Ingbar DH, Wendt $\mathrm{CH}$ : Oxidant effects on Na,K-ATPase: If only it were so simple. (Editorial) $J$ Lab Clin Med (In Press) 1997.

Ingbar DH, Wendt $\mathrm{CH}$, Crandell EC: Role of $\mathrm{Na}, \mathrm{K}-\mathrm{ATPase}$ in the resolution of pulmonary edema. in Ingbar DH, Matthay MA Eds.: Pulmonary Edema, volume in Lung Biology in Health \& Disease, L'Enfant, C., Ed. M. Dekker (In Press) 1998

Jewell EA, Shamraj OI, Lingrel JB. Isoforms of the $\alpha$ subunit of Na, K-ATPase and their significance. 
Acta Physiol Scand 146:161-169, 1992.

Julin CM, Zimmerman JJ, Sundaram V, and Chobanian MC. Activated neutrophils inhibit Na+ -K+ ATPase in canine renal basolateral membrane. Am J Physiol 262:C1364-C1370, 1992.

Kawakami K, Yanagisawa K, Watanabe Y, Tominaga S, Nagano K: Different factors bind to the regulatory region of the $\mathrm{Na}, \mathrm{K}-\mathrm{ATPase} \alpha-1$ subunit gene during the cell cycle. FEBS Lett 335:251-254, 1993.

Kawakami K, K Masuda, K Nagano, Y Ohkuma, RG Roeder. Characterization of the core promoter of the $\mathrm{Na} / \mathrm{K}$-ATPase $\alpha 1$ subunit gene: elements required for transcription by RNA polymerase II and III in vitro. Eur $J$ Biochem 237:440-446, 1996

Kim KJ, Suh DJ. Asymmetric effects of $\mathrm{H} 2 \mathrm{O} 2$ on alveolar epithelial barrier properties. Am J Physiol. 264:L308-315, 1993.

Kobayashi M, Kawakami K. ATF-1CREB heterodimer is involved in constitutive expression of the housekeeping Na,K-ATPase $\alpha-1$ subunit gene. Nucl Acids Res 23:2848-2855, 1995.

Lane LK: Functional expression of rat $\alpha 1 \mathrm{Na}, \mathrm{K}-\mathrm{ATP}$ ase containing substitutions for cysteines 454, 458, 459, 513 and 551. Biochem Molecul Biol Intl 31:817-822, 1993.

Lasnier J, OD Wangensteen, LS Schmitz, CR Gross, \& DH Ingbar. Terbutaline stimulates alveolar fluid reabsorption in hyperoxic lung injury J. Appl. Physiol. 81:1723-1729, 1996

Lescale-Matys L, Putnam DS, McDonough AA. $\mathrm{Na}^{+}-\mathrm{K}^{+}$-ATPase $\alpha_{1}$ - and $\beta_{1}$-subunit degradation: evidence for multiple subunit specific rates. Am J Physiol 264:C583-C590, 1993.

Lingrel JB, Orlowski J, Shull MM, Price EM. Molecular genetics of Na,K-ATPase. Progress in Nucl Acid Res 38:37-89, 1990

Liu B, Gick G. Characterization of the 5 ' flanking region of the rat $\mathrm{Na}+/ \mathrm{K}+-\mathrm{ATPase} \beta 1$ subunit gene. Biochim Biophys Acta 1130:336-338, 1992.

Matalon S: Mechanisms and regulation of ion transport in adult mammaliam alveolar type II pneumocytes. Am J Physiol 261:C727-738, 1991.

Matalon S, DJ Benos, RM Jackson: Biophysical and molecular properties of amiloride-inhibitable Na channels in alveolar epithelial cells. Am J Physiol 271:L1-L22,1996.

Matthay MA, Wiener-Kronish JP. Intact epithelial barrier function is critical for the resolution of alveolar edema in humans. Am Rev Respir Dis 142:1250-1257, 1990

Matthay MA, Folkesson HG, Verkman AS: Salt and water transport across alveolar and distal airway epithelia in the adult lung. Am J Physiol 270:L487-503, 1996.

McDonough AA, Geering K, Farley RA. The sodium pump needs its $\beta$ subunit. FASEB J. 4:1598$1605,1990 \mathrm{a}$.

McDonough AA, Tang M-J, Lescale-Matys L: Ionic regulation of the biosynthesis of Na,K-ATPase subunits. Semin Nephrol 10:400-409, 1990 b.

Meharg JV, McGowan-Jordan J, Charles A, Parmelee JT, Cutaia MV, Rounds S. Hydrogen peroxide stimulates sodium-potassium pump activity in cultured pulmonary arterial endothelial cells. Am J Physiol. 265:L613-L621, 1993.

Mircheff AK, Bowen JW, Yiu SC, McDonough AA. Synthesis and translocation of Na+-K+ATPase $\alpha$-and $\beta$-subunits to plasma membrane in MDCK cells. Am J Physiol 262:C470-C483, 1992.

Mishra OP, M Delivoria-Papadopoulos, G Cahillane, LC Wagerie. Lipid peroxidation as the mechanism of modification of the affinity of the NaK-ATPase active sites for ATP, K, Na and strophanthidin in vitro. Neurochem Res 14:845-851, 1989.

Nici L, Dowin R, Jamieson JD, Ingbar DH: Upregulation of rat type II pneumocyte $\mathrm{Na}, \mathrm{K}-\mathrm{ATPase}$ during hyperoxic lung injury. Am J Physiol 261:L307-314, 1991.

Nomoto M, Gonzales FJ, Mita T, Inoue N, Kawamura M. Analysis of cis-acting regions upstream of the rat Na/K-ATPase $\alpha$-1 subunit gene by in vivo footprinting. Biochim. Biophys Acta 1264:35$39,1995$. 
O'Brodovich H. Epithelial ion transport in the fetal and perinatal lung. Am J Physiol 261:C555564, 1991.

O'Brodovich HM. The role of active Na transport by lung epithelium in the clearance of airspace fluid. New Horizons 3:240-247, 1995.

Olivera WG, Ridge KM, Sznajder JI. Lung liquid clearance and Na, K-ATPase during acute hyperoxia and recovery in rats. Am J Respir Crit Care Med 152:1229-34, 1995.

Olivera W, Ridge K, Wood LDH, Sznajder JI. Active sodium transport and alveolar epithelial NaK-ATPase increase during subacute hyperoxia in rats. Am J Physiol. 266:L577-L584, 1994.

Panos R, Bak PM, Simonet WS, Rubin JS, Smith LJ. Intratracheal instillation of keratinocyte growth factor decreases hyperoxia-induced mortality in rats. $J$ Clin Invest 96:2026-2033, 1995. Planes C, Friedlander G, A Loiseau, C Amiel, C Clerici: Inhibition of Na-K-ATPase activity after prolonged hypoxia in an alveolar epithelial cell line. Am J Physiol 271:L70-L78,1996.

Ridge KM, Rutschman DH, Factor P, Katz AI, Bertorello AM, Sznajder JI. Differential expression of Na,K-ATPase isoforms in rat alveolar cells. Am J Physiol 273:L246-L255, 1997.

Robison T, Kim KJ. Enhancement of airway epithelial Na,K-ATPase activity by NO2 and protective role of nordihydroguaiaretic acid. Am J Physiol (Lung) 270:L266-L272, 1996.

Rushmore TH, Morton MR, Pickett CB. The antioxidant responsive element. J Biol Chem 266:1163211639, 1991.

Sakuma T, HG Folkesson, S Suzuki, G Okaniwa, S Fujimura, MA Matthay. Beta-adrenergic agonist stimulated alveolar fluid clearance in ex vivo human and rat lungs. Am J Respir Crit Car Med 155:506-512, 1997

Saumon G, Basset G: Electrolyte and fluid transport across the mature alveolar epithelium. $J$ Appl Physiol 74:1-15, 1993.

Schneeberger EE, McCarthy KM: Cytochemical localization of Na-K-ATPase in rat type II pneumocytes. J Appl Physiol 60:1584-1589, 1986.

Shull MM, Pugh DG, Lingrel JB. The human Na, K-ATPase al Gene: characterization of the 5'flanking region and identification of a restriction fragment length polymorphism. Genomics 6:451-460, 1990.

Skou JC: Overview: The Na,K-Pump. Meth Enzymol 156:1-25, 1988.

Suzuki S, D Zuege, Berthiaume Y. Sodium-independent modulation of Na,K-ATPase activity by $\beta$ adrenergic agonist alveolar type II cells. Am J Physiol 268:L983-990, 1995.

Sweadner KJ. Isozymes of the Na,K-ATPase. Biochim Biophys Acta 1989; 988:185-220.

Thet LA. Repair of oxygen-induced lung injury in: physiology of oxygen radicals. Am Physiol Soc, 87-107, 1986

Ueno S, M Kusaba, K Takeda, M Maeda, M Futai, F Izumi, M Kawamura. Functional consequences of subustitution of the disulfide-bonded segment, Cys127-Cys150, located in the extracellular domain of the Na,K-ATPase $\beta$ subunit: Arg148 is essential for the functional expression of Na,K-ATPase. $J$ Biochem 117:591-596, 1995.

Watanable YU, Kawakami K, Hirayama Y, Nagano K: Transcription factors positively and negatively regulating the Na,K-ATPase $\alpha$-1 subunit gene. J Biochem 114:849-855, 1993.

Wendt CH, H Towle, R Sharma, S Duvick, K Kawakami, G Gick \& Ingbar DH. Regulation of Na,KATPase gene expression in hyperoxia. Am J Physiol (Cell) (in press) 1997.

Yagawa Y, Kawakami K, Nagano K. Cloning and analysis of the 5'-flanking region of rat $\mathrm{Na}^{+} / \mathrm{K}^{+}$ATPase $\alpha-1$ subunit gene. Biochim Biophys Acta 1049:286-292, 1990.

Yagawa YS, Kawakami K, Nagano K. Housekeeping Na,K-ATPAse $\alpha-1$ subunit gene promoter is composed of multiple cis elements to which common and cell type-specific factors bind. Molec Cell Biol 12:4046-4055, 1992.

Yue G, Russell WJ, Benos DJ et al. Increased expression and activity of sodium channels in alveolar type II cells of hyperoxic rats. Proc Natl Acad Sci 92(18): 8418-22, 1995. 
Yue G, S Matalon. Mechanisms and sequelae of increased alveolar fluid clearance in hyperoxic rats. Am J Physiol 272:L407-L412, 1997.

Zheng LP, Du RS, Goodman BE. Effects of acute hyperoxic exposure on solute fluxes across the blood-gas barrier in rat lungs. J Appl Physiol 82:240-247, 1997.

Zolotarjova N. Ho C, Mellgren RL, Askari A, Huang Wu-h. Different sensitivities of native and oxidized forms of $\mathrm{Na}^{+} / \mathrm{K}^{+}$-ATPase to intracellular proteinases. Biochim Biophys Acta 1192:125-131, 1994.

Zuege D, Suzuki S, Berthiaume Y. Increase of lung sodium-potassium-ATPase activity during recovery from high permeability pulmonary edema. Am J Physiol 271:L896-L909, 1996. 